\title{
Diez signos emblemáticos a propósito de los noventa años de la Bauhaus
}

\author{
Ten emblematic signs: A reflection on ninety years of Bauhaus
}

<Resumen>

El 12 de abril de 2009 se cumplieron noventa años desde que Walter Gropius fuera designado director de las escuelas de arte y la de oficios existentes en Weimar, y que según la propuesta del arquitecto, fueron fundidas en la Sttatliche Bauhaus. La celebración internacional de este hecho tuvo en Berlín la exposición: Bauhaus, un modelo conceptual, considerada la más completa realizada hasta hoy y que luego fue trasladada a Nueva York. El aniversario motiva una reflexión que trata de insinuar una mirada a la paradigmática escuela de la modernidad, señalando sólo diez ejemplos, considerándolos como íconos emblemáticos de su producción, representándola.

$<$ Abstract $>$

On April 12, 2009 it was ninety years since Walter Gropius was named Dean of the Art School and the Arts and Crafts School, located in Weimar. Following a proposal by the architect, these two schools were merged to form the Stattliche Bauhaus. The international celebration of this act. which took place first in Berlin and later in New York, was an exhibition entitled «Bauhaus, a conceptual model», still considered the most complete Bauhaus exhibition to date. The anniversary of this event moved us to carry out a review of ten works of the Modern Movement which we consider to be emblematic and representative items of the Bauhaus production.

PALABRAS CLAVE

ARTE / BAUHAUS / GROPIUS / MODERNIDAD / OFICIOS

<KEYWORDS >

ART / BAUHAUS / GROPIUS / MODERNITY / CRAFTS
"Las cosas no son tan palpables y decibles como nos querrían hacer creer casi siempre; la mayor parte de los hechos son indecibles, se cumplen en un ámbito que nunca ha hollado una palabra; y lo más indecible de todo son las obras de arte, realidades misteriosas, cuya existencia perdura junto a la nuestra, que desaparece...».

Rainer María Rilke
Este año se han celebrado los noventa años de la Bauhaus, quizás la escuela más famosa de la historia, que en Weimar y en el año 1919, se inició con ciento cincuenta alumnos que acudieron a ella entusiasmados por el manifiesto fundacional que Walter Gropius (1883-1969) publicó ilustrado con un grabado del pintor Lionel Feininger (1871-1956). La imagen de esta xilografía representa una catedral con tres estrellas rodeando su torre, «símbolo cristalino de una nueva fe que ya se anuncia» decía el texto, aludiendo a una promesa de construcción donde debían confluir arquitectura, escultura y pintura, borrando las diferencias de clase entre artesanos y artistas, buscando su reencuentro en un proyecto donde la manualidad y la vuelta a los oficios sería lo esencial. Pero la

\footnotetext{
Artista visual Licenciado en Arte. Realiza docencia desde 1965; ha trabajado en todos los niveles de enseñanza, especializándose en los temas introductorios de forma para arquitectura, arte y diseño. Como investigador, editó en 2002 Carlos Hermosilla, artista ciudadano, adelantado del arte de grabar, Editorial Puntángeles, Valparaíso y en 2007 Edgardo Catalán. Una poética de la ausencia, Metales Pesados Libros, Santiago.
} 
imagen de la catedral transmitía además un sentido nacional que se había hecho presente en la resistencia alemana al poderío político y militar de Napoleón, tras desarticular el Sacro Imperio, actualizando el estilo gótico como un elemento de identidad que los pintores del romanticismo alemán usaron también como representación

En ese duro año diecinueve, sin embargo, las circunstancias surgían del fracaso de la aventura imperialista del Kaiser Guillermo II, quien abdicó, descabezando a un país sumido en la derrota, obligado a firmar el Tratado de Versalles que imponía duras condiciones de paz, una paz «ejemplarizadora». Pero «la seña gótica», desde antes de la Gran Guerra, significaba algunas otras cosas, porque en 1911, Willhelm Worringer (1881-1965) había publicado su libro FormProbleme DER GotIK ${ }^{[1]}$ desarrollando en él las condiciones del modelo teórico que había propuesto en su tesis de grado AbStRaktion und EInfüLUng, la que tres años antes había publicado en Munich ${ }^{[2]}$ fomentando entre los artistas el aprecio al expresionismo e incrementando la aceptación hacia los estilos no realistas.

A propósito del grabado en madera, debemos agregar que su renovación fue uno de los grandes aportes del expresionismo, redituando la técnica en la escena de vanguardia, la que, como antecedente de la impresión tipográfica, dotaba al dibujo de su reproductibilidad técnica como recurso propio de la gráfica, igualándola a la pintura y la escultura; un asunto fundamental para el espíritu moderno, que miraba con gran interés hacia el modelo británico que preconizaban las figuras más notables de Arts and Krafts: John Ruskin (1819-1900) y William Morris (1834-1896).

El naciente espíritu moderno combatía de ese modo la preeminencia exclusiva de la pintura, como la «reina de las artes», esencial en el pensamiento conservador de la tradición que sostenía La Academia de Roma, que menospreciaba todos los «otros oficios» definidos como «artes menores». Esta contraposición a La Academia, venía siendo expuesta por los espíritus "progresistas» como es el caso de Henry van de Velde (18631957), quien ya en el siglo diecinueve había iniciado su lucha contra el abuso artístico y pedagógico de los estilos del pasado, abogando permanentemente a favor de una síntesis del arte que debía estar encaminado hacia la formación de un «nuevo estilo»:

«Es necesario afirmar, desde el comienzo, que todas las denominaciones, tales como arte vulgar, arte de segunda categoría, arte industrial, artes aplicadas, artes útiles, sólo tienen valor en la medida en que se relacionan con objetos que hemos convenido en llamar así. Pero de ningún modo podrá admitirse que sean adecuadas o que exista realmente lo que ellas expresan ${ }^{[3]}$.

Henry van de Velde, natural de Amberes, «tuvo la sensibilidad de un sismógrafo», fue arquitecto, pintor, profesor de artes aplicadas y conferencista y llegó a la prehistoria de la Bauhaus cuando en 1902 se instaló en Weimar, para crear el SeminARIO dE ARTE InDUSTRIAL. En 1906, su estilo de enseñanza basado en el estudio elemental del trabajo en talleres, lo llevó a fundar la Escuela de Artes y Oficios, o Arte Industrial de Weimar, para la que diseñó el edificio y mantuvo su dirección hasta poco antes de la Gran Guerra, cuando acosado por la creciente xenofobia, tuvo que dimitir y abandonar Alemania. Ese fue un momento clave de esta historia, ya que para salvar la escuela, sugirió el nombre del joven Gropius como su posible sucesor. El arquitecto alemán, luego de vencer algunas resistencias, logró ser designado el 12 de abri de 1919, haciéndose cargo de la dirección de las dos escuelas que había propuesto reunir y reformular completamente, bautizándola: Statliches BauHaus de Weimar; pero a esa fecha, la de Artes y Oficios había sido ya desactivada y estaba casi completamente desmantelada, lo que motivo una de las primeras grandes dificultades de su gestión, ya que el único taller que quedaba más o menos completo era el de impresión y por eso pudo ser empleado.

Esa afortunada fecha del año diecinueve es la de esta celebración, porque definió a quien sería el conductor del proyecto de enseñanza más emblemático para el arte, el diseño y la arquitectura contemporáneas, lo que se daba en el marco de una reforma en la educación y en un panorama político de la más amplia democracia real que se abría en Alemania: la República de Weimar.

Ese momento abrió en Alemania la posibilidad de un cambio revolucionario, que como lo declaraba el manifiesto podía venir de la cultura. Ese período de diecinueve años, con todas sus contradicciones, fue sin duda un campo riquísimo de acción y reflexión, y proveyó la materia que está en el sustrato de la DIALÉCTICA DE LA ILUSTRACIÓN ${ }^{[4]}$. El programa escrito que llamaba a la nueva Escuela Estatal, procedía como lo habían estado haciendo las expresiones de la vanguardia artística desde que Marinetti, en 1909, abrió esa modalidad publicando su vitalista primer documento del futurismo en Le Figaro de París. Sin embargo, lo que se proponía no era un Ismo más, sino un planteamiento pedagógico nuevo, cuya complejidad experimental se centraba en el sentido de «la construcción», la que se ponía en escena desde el nombre que particularizaba al proyecto: Bauhaus, «la casa de la construcción»; verdadero acierto lingüístico de Gropius, con que logró marcar un antes y un después en la enseñanza de las disciplinas de proyecto, implicando en primer lugar a la moderna enseñanza del arte, a la naciente disciplina del diseño en todas sus manifestaciones, y a la arquitectura, entendida como la que les da lugar; pero también a otras disciplinas que por ese entonces eran nuevas, como son la fotografía ${ }^{[5]}$ o el cine. Este hecho, determinó su amplísimo campo de influencia para la sociedad «moderna», multiplicándose luego de 1933, el año de su cierre, pero sobre todo después del término de la Segunda Guerra Mundial.

La historia de la escuela es hoy extensamente conocida y su división de acuerdo a las ciudades que ocupó en Alemania corresponde más o menos a las tres direcciones que tuvo y pueden entenderse del siguiente modo: el de Weimar es el período del arte, marcado por un modo del expresionismo que salía de su aislamiento individual característico y que estaría representado por el «vorkurs» de Johannes Itten (1888-1967), el que en el orden docente es para muchos el aporte más señero de la Bauhaus ${ }^{[6]}$. El de Dessau, es el período que consolida al Diseño como la

Worringer, W. «La esencia del estilo gótico». Editorial Nueva Visión. Primera edición 1925. Buenos Aires, 1957.

[2] Worringer, Wilhelm. «Abstracción y naturaleza». Primera edición 1953Editorial del Fondo de Cultura Económica, México, 1966.. Worringer parte del supuesto «que la obra de arte se halla al lado de la naturaleza como un organismo autónomo equivalente» p. 17; este texto estimuló el arte abstracto.

[3] van de Velde. Henry «Observaciones generales para una síntesis del arte» en «Hacia un nuevo estilo». Editorial Nueva Visión, Buenos Aires, 1959, p. 32. Originalmente apareció en Bruselas como folleto (1895).

[4] Adorno, T., Horkeimer, M. «Dialéctica de la ilustración», primera edición manuscrita de 1940. Editorial Trotta, Barcelona, 1995.

[5] La fotografía no estuvo presente en el primer programa de Weimar, sólo se integro en Dessau.

[6] Acerca de la docencia, ver: Cruz, R. «Enseñanza de la Bauhaus» en revista CA N 47, Santiago 1987, por el aniversario 67, y Wick, R. «La pedagogía de la Bauhaus», Alianza Editorial, Madrid, 1986. 
nueva disciplina proyectual, desarrollado bajo el signo racional que buscaba la modernidad y corresponde al Nuevo Espíritu o «La Nueva Visión» ${ }^{[7]}$; en este período la Bauhaus contó con inmejorables instalaciones para su funcionamiento y la comodidad creativa de maestros y estudiantes. Pero los diversos conflictos que ya impactaban la escuela, impulsaron a Gropius a dejar su dirección en manos del arquitecto suizo Hannes Meyer (1889-1954), quien había llegado para dictar el curso de construcción, pero una vez instalado en la dirección, cuestionó el «exceso de arte» y reformuló el plan de estudio mientras la escuela se politizaba al ritmo de la confrontación que la sociedad experimentaba, tensándose al máximo con la creciente y agresiva organización de la derecha alemana. Gropius instalado profesionalmente en Berlín, logró mover entonces los hilos de una compleja negociación, para desplazar a Meyer, convenciendo a Mies van der Rohe (1886-1969), para ocupar el cargo se iniciaba con ello el período postrero de la Bauhaus, transformada ahora en escuela de arquitectura, cuando Mies, de reconocido apoliticismo, remueve a gran cantidad de alumnos. Pero la administración de la ciudad de Dessau, a pesar de la garantía por estas nuevas condiciones, le quitó el apoyo, y el flamante director debió trasladar a Berlín una escuela mermada en alumnos y recursos; fue su breve último período funcionalista. No podía permanecer, porque el nacionalsocialismo controlaba ya el poder en Alemania y determinó su cierre definitivo; era además el inicio de la «purificación», ya que para los nazis, la institución no era sino un reducto de artistas degenerados, bolcheviques, y judíos ${ }^{[8]}$.

Tras la Segunda Guerra, los lugares que habitó la escuela quedaron separados, divididos como la propia Alemania. La reunificación del país repotenció en el fin del siglo la información sobre su legado y en su estudio, hoy se identifica claramente en sus contradicciones, coincidentes con los de la República de Weimar que fue su marco histórico.

Actualmente la información sobre la Bauhaus circula en cantidad de publicaciones, lo que ha permitido que se vaya perdiendo la inclinación a considerarla como un fenómeno en sí, o a ser observada, como se hizo la mayoría de las veces: en la absolutización geométrica de algunas de sus prácticas y con los colores elementales de su abc ${ }^{[9]}$. Sin embargo, la unidad básica constructiva demarcada por el hexaedro y modulada como un espacio al infinito es una de sus imágenes emblemáticas, como en el famoso dibujo axonométrico coloreado del "proyecto de despacho» de Gropius, preparado aparentemente para la gran exposición 1923 por uno de sus ayudantes ${ }^{[10]}$; ese mismo despacho, pero como «una realidad», podemos verlo también en un registro fotográfico a color, con apariencia de autocromo, que posiblemente tuvo el mismo objetivo demostrativo del dibujo, pero aportando algunos otros antecedentes documentales de su ambientación, como son la iluminación proveniente de la gran ventana, el tapiz, la alfombra y la lámpara, obras respectivas de los alumnos: Else Mogeln, Gertrud Arndt y Wilhelm Wagenfeld.

Como profesores, deberíamos preguntarnos por las enseñanzas que nos deja la escuela, ya que siempre hay algo de ella en el diseño de nuestros ejercicios. Como profesionales deberíamos preguntarnos también por sus alcances e influencia. Culturalmente podríamos preguntarnos cuáles podrían ser los signos más emblemáticos que nos aporta su patrimonio; por eso es que hemos pensado en la xilografía de Feininger o en las representaciones del despacho de Gropius que hemos referido, pero quisiéramos agregar otros, para completar los diez ejemplos que consideramos muy especialmente significativos:

1. El currículum circular, que con sus cuatro anillos expresa la primera escuela y su aporte a la educación, donde la circularidad de su trazado concéntrico, parece centrarla más en el sujeto en formación que en considerar al organigrama como un instrumento operacional de cursos encadenados, como solemos verla en los modelos de formación de una industria educativa que parece cada vez más sustentada en el negocio. Este esquema, dibujado en 1923, si bien correspondía al plan inicial era temporalmente coincidente con un primer desplazamiento de profesores marcado por la salida de Itten y el traslado de la escuela a Dessau, o cierre del primer período. En el gráfico, el anillo periférico corresponde a la «Enseñanza preliminar marcado por la enseñanza elemental de la forma, con el objetivo de ampliar, en el «taller didáctico», la sensibilidad del alumno acerca de la materia. El segundo anillo, subdividido en cinco campos, indica un estudio algo más racional o teorizante acerca de la naturaleza, de los materiales, del espacio, del color y la «composición», trabajando en construcciones y representaciones. La condición de todo el modelo de la escuela se basaba en el concepto de maestro, con que Gropius había reemplazado a la tradicional figura autoritaria del Herr Professor, una verdadera institución en Alemania. El tercer anillo, está subdividido en siete casillas, indicándose en cada una de ellas un material y corresponde a los talleres de: «Madera, Metal, Tejidos, Color, Vidrio, Arcilla, Piedra». El cuarto y último anillo, es en realidad un círculo y es el centro del sistema o punto de llegada. En él se puede leer: "Construción, OBRA, lugar de experimento, Proyecto de Arquitectura e Ingeniería», el mundo del proyecto como posible.

\section{El edificio de la escuela en Dessau, no} puede dejar de ser considerado entre los proyectos emblemáticos, que en este caso ciertamente no es de ella misma como escuela, sino de quien la imaginó e impulsó, y siguió observándola, cuando ya no pertenecía, velando por ella desde lejos. Esta obra de Gropius es de 1924 y se conecta consecuentemente con toda la obra que había comenzado muy joven cuando proyectó el gran muro vidriado de la fábrica de Fagus en Alfeld an der Leine, dándole con su notoriedad la condición necesaria para pertenecer al movimiento del Werkbund alemán. Pero cuando apreciamos este edificio de la escuela, no se puede dejar de considerar al resto del proyecto, con las viviendas de los maestros y los departamentos en altura para los alumnos, como sistema total.

[7] «Von material zu architectur» de Lazlo Moholy Nagy fue el № 14 de los Bauhausbücher, 1929; Gropius lo consideró la "gramática» de la escuela. Su versión inglesa: «The New Vision», apareció en Nueva York en 1930. La primera en español «La nueva visión y reseña de un artista», Editorial Nueva Visión, Buenos Aires, 1963 y es traducción de la edición de 1947.

[8] Cuatro años después del cierre de la Bauhaus, una comisión designada por Hitler requisó más de cinco mil piezas de arte moderno (expresionismo, dadaísmo y cubismo) con el fin de exponerlas en paralelo a la de «Arte Alemán» y demostrar con ello la superioridad del arte que propiciaban. Entartete Kunst, Arte Degenerado, se inauguró el 19 de julio de 1937 en Munich y tuvo un éxito de público muy superior al del arte oficial.

[9] Abbott Miller, Ver Lupton, E. «El abc de la Bauhaus y la teoría del diseño». Editorial Gustavo Gili, Barcelona, 1994.

10] Kennedy, A. "Bauhaus», Edimat Libros, Madrid, 2008, p. 305

[11] Kahn Louis. «Forma y diseño» Ediciones Nueva Visión, Buenos Aires 1965, p. 8. 
3. Otra obra arquitectónica que no puede dejar de ser considerada en este marco, es la casa Haus am Horn de Georg Muche (1895- 1986); ella fue construida para la exposición de 1923 y fue considerada como un modelo del sistema con su equipamiento, mostrando con ello la concepción de globalidad que sostenía la escuela y que deberíamos reconocer en la visión de hoy, como un modelo de «vivienda social».

4. El ajedrez de Josef Hartwig (1880-1956) es un modelo demostrativo de la elaboración de objetos cotidianos; creado en 1924 fue comercializado con éxito y por su sentido geométrico expresa plenamente el sistema de "preferencias formalizadoras». Nacía el diseño como disciplina y pudiéramos señalarlo desde hoy como una modificación del significante sin alteración del significado, o bien como lo modificable de una forma que permanece, tal como lo señala el arquitecto Louis Kahn (1901-1974) en uno de sus textos más conocidos: "La forma es el qué. El diseño es el cómo. La Forma es impersonal, el Diseño pertenece al diseñador» ${ }^{[11]}$. Pero hay otro aspecto interesante a señalar de proyecto de Hartwig, y es que también nos hace presente el sentido que tenía el juego y el esparcimiento en la vida cotidiana de la escuela, o extendiendo más su comprensión, el sentido lúdico que tenía también toda su actividad, incluida la docente; pareciendo recoger en ello el significado que el poeta Friedrich Schiller (1759-1805) había dado al juego como centro o base de la educación estética del hombre, y que lo lleva a decir categóricamente en su carta decimoquinta: «Porque digámoslo de una vez: sólo juega el hombre cuando es hombre en el pleno sentido de la palabra, y sólo es plenamente hombre cuando juega...» ${ }^{[12]}$.

5. Entrando de lleno en los objetos o productos de diseño, no se puede pasar por alto el sillón de brazos Wassily, la famosa obra de Marcel Breuer (19021981), comercializada hasta el día de hoy. Este «mueble» de 1925, recoge aspectos de la propia historia de la escuela; en primer lugar la problemática del mobiliario que concentró el trabajo de dos talleres, el de madera y el de metales. En el de madera se realizaron las primeras aproximaciones, donde el modelo que no puede perderse de vista es la silla de Rietvelt ${ }^{[13]}$ y que refleja el tránsito de las ideas del movimiento De Stijl a través de la enseñanza «informal» con que Van Doesburg (1883-1931) logró imponer con su presencia, algo prepotente, en Weimar; pero que lleva también a la búsqueda de materiales innovadores para el mobiliario como es el tubo de acero y los planos de material tensado por las acciones estructurales características de este sillón que, posteriormente y para su comercialización, fue bautizado en homenaje a uno de los maestros más persistentes de la escuela ${ }^{[14]}$. En el archivo se guardan dos fotos del sillón en uso, una de 1928 tomada en Dessau, donde vemos al maestro Joseph Albers (18881976) con polainas y mirando fijamente a la cámara, en un ambiente donde la única «decoración» es una pintura suya sobre vidrio ${ }^{[15]}$. La otra, es la de una joven desconocida, no demasiado formal por su vestimenta, pero de «tacos» y con el rostro cubierto por una máscara de las que Oskar Schlemmer (1888-1943) usaba para las actividades de accionismo performático teatral que se practicaban en la escuela ${ }^{[16]}$.

6. Entre las innumerables piezas gráficas que produjo la escuela hay muchas que resultan atractivas, pero la que nos resulta muy significativa es el cartel del cincuenta aniversario de la Bauhaus, donde Herbert Bayer (1900-1985), en 1968, sintetizó el modo formal del concepto de iniciación con figuras regulares, poliedros y colores, valores formales de la enseñanza básica como un resumen gráfico pregnante, recalcando de paso la importancia de la abstracción y el valor de la Gestalt, aunque ésta, en el sentido de la psicología, tuvo mayor presencia posteriormente, en la Bauhaus de Norteamérica.

7. No hay duda que los medios de comunicación visual tienen ese «resplandor intelectual de las imágenes» de lo emblemático, y preferiríamos, cuando se trata del cartel, llamarla «imagen gráfica». Sin una necesaria voluntad de comunicación, pero si con la de conservar congelado algo que estuvo allí y convierte al fotógrafo en testigo, prolongando con su registro la existencia de ambos; la fotografía transmite también ese emblemático sentido, lo que hace de su observación una lectura que puede develar sus intenciones. En este sentido pensamos que la imagen fotográfica que más representa lo que podríamos llamar una atmósfera Bauhaus, es la que tomó Joost Schmidt en 1932, posiblemente en su taller y al parecer con una Zeiss Ikon de doble objetivo. Se trata de un «Stilleben», en el sentido del género pictórico, o sea una composición de objetos inanimados, siete de ellos geométricos y diferentes entre sí por tamaño y material; ellos ocupan el cuarto inferior de la imagen, colocados sobre un anaquel adosado al muro que enfrenta paralelamente el plano focal del encuadre, el que lo corta por ambos lados; constituyéndose, como conjunto, una realidad plana y poco profunda. Por detrás de los cuerpos de cristal, que ocupan la zona derecha y cubriendo casi completamente el muro en que se apoya hasta casi tocar el borde superior de la imagen, hay una placa perforada con el perfil de una figura femenina que, cortada a la altura de las rodillas, mira hacia la fuente de luz que viene de la izquierda y parece provenir de una ventana; dentro del vano y correspondiendo exactamente con el perfil del recorte, hundido o encajado en él, hay un maniquí descabezado y sin brazos, donde el vacío sobre los hombros formaliza la cabeza faltante, completando la figura y dándole un aspecto "metafísico», que parece emparentarla a un de Chirico temprano ${ }^{[17]}$. El único cuerpo metálico es una esfera bruñida que en la repisa toca el borde izquierdo del panel, marcando por la base lo que sería el centro vertical de la imagen; un número nueve, diagonal a la escena, dibujado sobre uno de los poliedros mayores y opacos de la izquierda, con su literalidad cifra lo enigmático, porque la contabilidad sólo

Schiller, J.C. F. «La educación estética del hombre», Editorial Arte y Literatura, La Habana, 1984, p. 84

[13] Gerrit Thomas Rietvelt (1888-1964) fue hijo de un mueblista y en su taller comenzó como aprendiz, mucho antes de estudiar arquitectura. Su silla, definida en alguna literatura como «Azul-grana», data de 1917-18 y el carácter de sus planos y líneas que parecen flotar, se incrementa por el acabado en esmalte negro, azul, rojo y amarillo; esto determinó que fuera considerada «un manifiesto» por el grupo Der Stijl y ejerciera su influencia en las búsquedas del taller de madera en la Bauhaus.

Wassily Kandinsky (1866-1944) fue el profesor que permaneció más en la escuela, desde el año veintidós y hasta el cierre.

Ver Droste, M. «Bauhaus Archiv», Editorial Taschen, Köln, 2006, p. 141

Ver Droste,
Ibid, p. 152.

[17] Giorgo de Chirico (1888-1978) pintor italiano cuya inquietante obra inicial, se considera una de las fuentes inmediatas el surrealismo. El academismo de su obra posterior, fue rechazado por sus admiradores iniciales. 
puede ser exacta si la figura femenina, compuesta como un relieve, deja de ser una, y logramos pensarla como figura y fondo, algo que nos cuesta hacer, en forma natural al menos.

8. Para terminar, debemos señalar que entre los productos de la Bauhaus, nuestra preferencia más estimada es la tetera de cristal de Jena diseñada en los años veinte por Wilhelm Wagenfeld (1900-1990). La razón de la grandeza de este objeto es que su diseño hizo coincidir la belleza formal de su propuesta, con la innovación industrial aportada por Jena ${ }^{[18]}$ donde se había perfeccionado el vidrio refractario. Wagenfeld ${ }^{[19]}$ encontró en ese material las condiciones para esta tetera que, con los anhelos de la modernidad hizo visible la preparación de la infusión. Otros productos domésticos de diseño se fueron agregando a la industria del vidrio, pero sigue siendo esta magnífica tetera de Jena Glass una pieza de indiscutible refinamiento.

Más allá de la denominación Bauhaus cuyos ochenta años hemos celebrado, deberíamos quizás escuchar a Mies van der Rohe, quien en su conferencia por el setenta cumpleaños de Walter Gropius, afirmó:

"La Bauhaus era una idea y creo que el motivo principal de la enorme influencia que ha tenido en el mundo se ha de buscar en el hecho de que era una idea... Sólo una idea tiene fuerza para expandirse tanto» ${ }^{20]}$

Las ideas efectivamente son como una piedra arrojada en la pendiente del tiempo, nacen para seguir rodando y si bien a veces, las instituciones parecieran tener su tiempo limitado, como el de los hombres, «...la historia de la Bauhaus no puede considerarse completa sin echar una rápida mirada al gran éxito que la institución tuvo en América...» como ha señalado Elaine S. Hochman ${ }^{[21]}$ y deberíamos afirmar que no hay escuela en el mundo que no derive de su experiencia fundadora, esto es lo que valida que ya en camino de su centenario, nos sigamos preguntando qué es lo que tenemos de la Bauhaus en nuestras escuelas de arte y de diseño, así como en nuestras escuelas de arquitectura que, enriquecidas por la modernidad con el concepto del espacio, permanece en la voluntad de dar lugar y hospedar la vida del hombre, junto al extenso mundo de los objetos que, funcionales o simbólicos, constituyen su entorno.

\section{Referencias bibliográficas}

Abbott M., Lupton E., «El abc de la Bauhaus y la teoría del diseño. Editorial Gustavo Gili, Barcelona, 1994
Adorno, T., Horkeimer, M. «Dialéctica de la ilustración», primera edición manuscrita de 1940. Editorial Trotta, Barcelona, 1995

Cruz, R. «Enseñanza de la Bauhaus» en revista CA N 47, Santiago 1987.

Droste, M. «Bauhaus Archiv». Editorial Taschen, Köln, 2006.

Hochman, E. «La Bauhaus crisol de la modernidad». Ediciones Paidos Ibérica, Barcelona, 2002.

Kahn L. «Forma y diseño». Ediciones Nueva Visión, Buenos Aires 1965.

Kennedy, A. «Bauhaus». Edimat Libros, Madrid, 2008.

Moholy N., L. «La nueva visión y reseña de un artista», Editorial Nueva Visión, Buenos Aires, 1963

Puente, Moisés (ed.) «Conversaciones con Mies van der Rohe», Editorial Gustavo Gili, Barcelona, 2006.

Schiller, F. «La educación estética del hombre». Editorial Arte y Literatura, La Habana, 1984

Van de Velde, H. «Hacia un nuevo estilo» Editorial Nueva Visión, Buenos Aires, 1959.

Wick, R. «La pedagogía de la Bauhaus», Alianza Editorial, Madrid, 1986.

Worringer, W. «La esencia del estilo gótico». Primera edición 1925. Editorial Nueva Visión, Buenos Aires, 1957

Worringer, W. «Abstracción y naturaleza». Primera Edición 1953. Editorial del Fondo de Cultura Económica, México, 1966.

[18] Jena es una ciudad junto al río Saale, al este de Weimar; rodeada de montañas calcáreas, la localidad es famosa por su producción industrial, que cubre muchas cosas, entre ellas la del cristal existe desde finales del s. XIX, cuando los profesionales e inventores Schott, Abbe y Zeiss, coincidieron para fundar el Laboratorio de Tecnología del Vidrio y luego la empresa Jenaer Glaswerk \& Gen que creó el «cristal de Jena» un vidrio de borosilicato que reduce su coeficiente de dilatación térmica, haciéndolo resistente a los cambios de temperatura. También en el campo de los cristales ópticos, Carl Zeiss fijó su nombre en la historia de la fotografía.

[19] Cuando Wilhelm Wagenfeld (1900-1990) llegó a la Bauhaus, era ya platero, con grado de oficial. Se inscribió sin embargo como alumno en la escuela de Weimar, recibiendo inicialmente la influencia de Marianne Brandt (1893-1983) en el estilo de su trabajo. A principio de los veinte, con el estudiante suizo Karl Jacob Jucker (1902-1997) realizaron una lámpara de mesa, que ha sido uno de los objetos de diseño más celebrados y se encuentra en la colección del Moma. Diseñador sobresaliente, su experiencia docente la publicó en 1948: «Wesen und Gestal», libro que ha sido reeditado en 1990 como «Wesen und Gestalt der Dinge un uns». Su ciudad natal, Bremen, mantiene el Museo Wilhelm Wagenfeld Haus dedicado a su memoria.

[20] Ver Puente, M.(ed.) «Conversaciones con Mies van der Rohe», Editorial Gustavo Gili, Barcelona, 2006 p. 63.

[21] Hochman, E. «La Bauhaus crisol de la modernidad» Ediciones Paidós Ibérica, Barcelona, 2002, p. 376. 